\title{
Effect of spironolactone in patients with resistant arterial hypertension in relation to age and sex: Insights from the aspirant trial
}

\author{
Jan Vaclavika, Richard Sedlak ${ }^{\mathrm{b}}$, Jiri Jarkovskyc, Eva Kocianovaa ${ }^{\mathrm{a}}$, Milos Taborsky $^{\mathrm{a}}$
}

\begin{abstract}
Background. There are currently limited data on whether the effect of spironolactone in patients with resistant arterial hypertension depends on age and sex.

Methods. Patients with an office systolic blood pressure (BP) $>140 \mathrm{mmHg}$ or diastolic BP $>90 \mathrm{mmHg}$, despite treatment with at least 3 antihypertensive drugs including a diuretic, were randomly assigned to receive spironolactone or a placebo for 8 weeks in a double-blind, placebo-controlled, multicentre trial (ASPIRANT).

Results. Analyses were done on 55 patients treated with spironolactone and 56 patients treated with placebo. Significant reductions of office systolic BP $(-8.9 \pm 6.7 \mathrm{mmHg}, P=0.012), 24-\mathrm{h}$ ABPM systolic BP $(-7.9 \pm 7.2 \mathrm{mmHg}, P=0.032)$ and ABPM day-time systolic BP $(-7.5 \pm 7.1 \mathrm{mmHg})$ after 8 weeks of spironolactone treatment, compared to placebo, were only observed in patients with a median age $>62$ years. The office and ABPM systolic BP reductions in patients aged $\leq 62$ years and diastolic BP reductions by spironolactone in both age groups were not significant compared to placebo. Women tended to have a nonsignificantly higher reduction in systolic BP with spironolactone treatment, and there was no difference in diastolic BP reduction between women and men.

Conclusions. Spironolactone only leads to a reduction of systolic BP in older patients with resistant arterial hypertension aged $>62$ years, and is effective to a similar extent in men and women.

Key words: resistant hypertension, spironolactone, blood pressure, age, sex

Received: April 10, 2012; Accepted with revision: November 27, 2012; Available online: December 7, 2012

http://dx.doi.org/10.5507/bp.2012.105

${ }^{a}$ Department of Internal Medicine I - Cardiology, University Hospital Olomouc and Faculty of Medicine and Dentistry, Palacky University Olomouc, Czech Republic

${ }^{b}$ Department of Internal Medicine, Prostejov Hospital, Prostejov

'Institute of Biostatistics and Analyses, Faculty of Medicine and Faculty of Science, Masaryk University, Brno

Corresponding author: Jan Vaclavik, e-mail:vaclavik.j@centrum.cz
\end{abstract}

\section{INTRODUCTION}

Resistant hypertension is defined as blood pressure (BP) that remains above goal in spite of the concurrent use of 3 antihypertensive agents of different classes prescribed at optimal dosages; one of the 3 agents used should be a diuretic ${ }^{1}$.

Spironolactone is a mineralocorticoid receptor antagonist which was shown to lower blood pressure effectively in patients with resistant arterial hypertension. A number of uncontrolled trials showed the positive effect of small doses of spironolactone $(25-50 \mathrm{mg})$ in lowering blood pressure in patients with resistant arterial hypertension $^{2-12}$. The addition of spironolactone to other antihypertensive medications usually led to a marked decrease of systolic BP (-14 to $-36 \mathrm{mmHg}$ ) and diastolic BP (-7 to $-12.5 \mathrm{mmHg}$ ) (ref. $\left.{ }^{13}\right)$. A recent randomized, double-blind, placebo-controlled, multicentre trial (ASPIRANT) found a significant decrease of systolic, but not diastolic BP, with the addition of $25 \mathrm{mg}$ of spironolactone compared to a placebo in patients with resistant hypertension ${ }^{14}$.

Currently, it is not completely clear how to identify patients for which treatment with spironolactone is most effective. There are only limited data on whether the effect of spironolactone treatment in patients with resistant arterial hypertension depends on age and sex. Therefore, we decided to perform a post-hoc analysis of the data from the randomized ASPIRANT trial ${ }^{14}$.

\section{METHODS}

ASPIRANT was an investigator-led, prospective, multicentre, randomized, double-blind, placebo-controlled, parallel-group trial. The design and main results of the trial have been described previously ${ }^{14,15}$. In brief, we enrolled patients older than 18 years with resistant arterial hypertension, defined as office systolic BP >140 or diastolic BP >90 $\mathrm{mmHg}$ despite being treated with at least three antihypertensive drugs, including a diuretic. Patients with diabetes or chronic kidney disease (defined as serum creatinine $>133 \mu \mathrm{mol} / \mathrm{L}$ or proteinuria $>300 \mathrm{mg} /$ day) were enrolled if the office BP was $>130 / 80 \mathrm{mmHg}$.

For safety reasons, we excluded all patients with severe hypertension (systolic BP $>180$ or diastolic BP > 110 $\mathrm{mmHg}$ ), those with renal insufficiency with serum creatinine $>180 \mu \mathrm{mol} / 1$ or glomerular filtration rate $<40 \mathrm{~mL} /$ min calculated by the MDRD formula, hyperkalemia $>5.4 \mathrm{mmol} / \mathrm{L}$, hyponatremia $<130 \mathrm{mmol} / \mathrm{L}$, porphyria, pregnant or lactating women or women of fertile age not using effective contraception, patients with known prior hypersensitivity to the drug Verospiron (spironolactone; 
Table 1. Patient demographics and baseline characteristics according to age groups.

\begin{tabular}{|c|c|c|c|}
\hline Patient characteristics & Below median age & Above median age & $P$ \\
\hline Age (years) & $\leq 62$ & $>62$ & \\
\hline Spironolactone group (N) & 28 & 27 & \\
\hline \multicolumn{4}{|l|}{ Demographic characteristics } \\
\hline Sex (female) & $7(25.0 \%)$ & $11(40.7 \%)$ & 0.259 \\
\hline Height (cm) & $175.8( \pm 9.3)$ & $170.3( \pm 7.5)$ & 0.012 \\
\hline Weight (kg) & $103.1( \pm 18.5)$ & $90.5( \pm 12.9)$ & 0.004 \\
\hline $\operatorname{BMI}\left(\mathrm{kg} / \mathrm{m}^{2}\right)$ & $33.4( \pm 5.9)$ & $31.1( \pm 3.8)$ & 0.104 \\
\hline Heart rate $(\mathrm{bpm})$ & $70.2( \pm 10.4)$ & $65.3( \pm 9.9)$ & 0.049 \\
\hline \multicolumn{4}{|l|}{ Systolic BP } \\
\hline ABPM day-time BP (mmHg) & $146.6( \pm 16.1)$ & $142.7( \pm 13.4)$ & 0.368 \\
\hline ABPM night-time $\mathrm{BP}(\mathrm{mmHg})$ & $134.3( \pm 19.5)$ & $138.5( \pm 18.6)$ & 0.354 \\
\hline 24-h ABPM BP (mmHg) & $143.9( \pm 15.3)$ & $142.3( \pm 11.7)$ & 0.873 \\
\hline Office BP (mmHg) & $153.1( \pm 11.5)$ & $156.8( \pm 9.0)$ & 0.245 \\
\hline \multicolumn{4}{|l|}{ Diastolic BP } \\
\hline ABPM day-time BP (mmHg) & $87.6( \pm 11.4)$ & $79.4( \pm 9.3)$ & 0.002 \\
\hline ABPM night-time $\mathrm{BP}(\mathrm{mmHg})$ & $78.8( \pm 10.5)$ & $74.5( \pm 15.7)$ & 0.148 \\
\hline 24-h ABPM BP (mmHg) & $84.1( \pm 10.2)$ & $77.9( \pm 9.4)$ & 0.016 \\
\hline Office BP (mmHg) & $96.9( \pm 9.7)$ & $88.2( \pm 10.0)$ & $<0.001$ \\
\hline \multicolumn{4}{|l|}{ Baseline serum laboratory characteristics } \\
\hline $\mathrm{Na}(\mathrm{mmol} / \mathrm{L})$ & $139.7( \pm 2.4)$ & $141.1( \pm 3.0)$ & 0.085 \\
\hline $\mathrm{K}(\mathrm{mmol} / \mathrm{L})$ & $4.2( \pm 0.4)$ & $4.1( \pm 0.5)$ & 0.926 \\
\hline $\mathrm{Cl}(\mathrm{mmol} / \mathrm{L})$ & $103.7( \pm 3.6)$ & $104.2( \pm 4.0)$ & 0.697 \\
\hline Urea $(\mathrm{mmol} / \mathrm{L})$ & $5.7(3.8 ; 9.7)$ & $6.2(4.0 ; 10.4)$ & 0.285 \\
\hline Creatinine $(\mu \mathrm{mol} / \mathrm{L})$ & $80.0(53.0 ; 107.0)$ & $83.0(66.0 ; 128.0)$ & 0.151 \\
\hline Glycaemia (mmol/L) & $6.4(4.6 ; 20.3)$ & $5.9(5.0 ; 9.1)$ & 0.972 \\
\hline Plasma renin activity $(\mathrm{ng} / \mathrm{mL} / \mathrm{h})$ & $0.7(0.1 ; 5.8)$ & $0.2(0.1 ; 4.0)$ & 0.087 \\
\hline Aldosterone (ng/L) & $101.0(50.0 ; 261.0)$ & $79.0(21.0 ; 297.0)$ & 0.102 \\
\hline Aldosterone/renin ratio ${ }^{\dagger}$ & $13.8(1.6 ; 196.9)$ & $16.0(1.3 ; 297.0)$ & 0.364 \\
\hline \multicolumn{4}{|l|}{ Medication at randomization } \\
\hline Angiotensin-converting enzyme inhibitor & $25(89.3 \%)$ & $17(63.0 \%)$ & 0.029 \\
\hline$\beta$ blocker & $20(71.4 \%)$ & $21(77.8 \%)$ & 0.758 \\
\hline Calcium channel blocker & $25(89.3 \%)$ & $24(88.9 \%)$ & 1.000 \\
\hline Diuretics & $28(100.0 \%)$ & $27(100.0 \%)$ & - \\
\hline Angiotensin II receptor blocker & $11(39.3 \%)$ & $14(51.9 \%)$ & 0.422 \\
\hline$\alpha$ blocker & $1(3.6 \%)$ & $7(25.9 \%)$ & 0.025 \\
\hline Centrally acting antihypertensives & $19(67.9 \%)$ & $13(48.1 \%)$ & 0.176 \\
\hline Other antihypertensives & $2(7.1 \%)$ & $0(0.0 \%)$ & 0.491 \\
\hline Median number of antihypertensives & $5.0(3.0 ; 6.0)$ & $4.0(3.0 ; 6.0)$ & 0.644 \\
\hline
\end{tabular}

Data are mean $(\mathrm{SD})$ when normally distributed and median $\left(5^{\text {th }}\right.$ and $95^{\text {th }}$ percentile range) when they have non-normal distributions. Categorical variables are number (\%). Statistical significance was tested by Mann Whitney $U$ test.

${ }^{\dagger}$ Calculated as serum aldosterone $(\mathrm{ng} / \mathrm{L}) /[10 \mathrm{x}$ plasma renin activity $(\mathrm{ng} / \mathrm{mL} / \mathrm{h})]$. 
Table 2. Patient demographics and baseline characteristics according to sex.

\begin{tabular}{|c|c|c|c|}
\hline Patient characteristics & Men & Women & $P$ \\
\hline Spironolactone group $(\mathrm{N})$ & 37 & 18 & \\
\hline \multicolumn{4}{|l|}{ Demographic characteristics } \\
\hline Age (years) & $60.4( \pm 10.6)$ & $63.3( \pm 7.1)$ & 0.293 \\
\hline Height $(\mathrm{cm})$ & $177.3( \pm 6.5)$ & $164.6( \pm 6.6)$ & $<0.001$ \\
\hline Weight (kg) & $101.4( \pm 16.4)$ & $87.8( \pm 15.0)$ & 0.010 \\
\hline BMI $\left(\mathrm{kg} / \mathrm{m}^{2}\right)$ & $32.2( \pm 4.8)$ & $32.4( \pm 5.7)$ & 0.921 \\
\hline Heart rate $(\mathrm{bpm})$ & $67.5( \pm 10.5)$ & $68.4( \pm 10.4)$ & 0.614 \\
\hline \multicolumn{4}{|l|}{ Systolic BP } \\
\hline ABPM day-time BP (mmHg) & $143.3( \pm 13.6)$ & $147.4( \pm 17.2)$ & 0.609 \\
\hline ABPM night-time BP (mmHg) & $134.2( \pm 18.4)$ & $140.8( \pm 20.0)$ & 0.209 \\
\hline 24-h ABPM BP (mmHg) & $141.5( \pm 12.8)$ & $146.4( \pm 14.7)$ & 0.222 \\
\hline Office BP (mmHg) & $153.4( \pm 10.3)$ & $158.1( \pm 10.2)$ & 0.181 \\
\hline \multicolumn{4}{|l|}{ Diastolic BP } \\
\hline ABPM day-time BP (mmHg) & $84.6( \pm 9.6)$ & $81.4( \pm 13.8)$ & 0.209 \\
\hline ABPM night-time BP (mmHg) & $77.4( \pm 11.2)$ & $75.2( \pm 17.3)$ & 0.479 \\
\hline 24-h ABPM BP (mmHg) & $82.0( \pm 9.0)$ & $79.1( \pm 12.5)$ & 0.190 \\
\hline Office BP (mmHg) & $93.5( \pm 9.7)$ & $90.8( \pm 12.7)$ & 0.360 \\
\hline \multicolumn{4}{|l|}{ Baseline serum laboratory characteristics } \\
\hline $\mathrm{Na}(\mathrm{mmol} / \mathrm{L})$ & $140.4( \pm 3.2)$ & $140.5( \pm 2.0)$ & 0.921 \\
\hline $\mathrm{K}(\mathrm{mmol} / \mathrm{L})$ & $4.2( \pm 0.5)$ & $4.1( \pm 0.5)$ & 0.865 \\
\hline $\mathrm{Cl}(\mathrm{mmol} / \mathrm{L})$ & $103.8( \pm 4.1)$ & $104.3( \pm 3.2)$ & 0.413 \\
\hline Urea $(\mathrm{mmol} / \mathrm{L})$ & $6.2(3.8 ; 11.6)$ & $5.3(3.3 ; 10.4)$ & 0.203 \\
\hline Creatinine $(\mu \mathrm{mol} / \mathrm{L})$ & $90.0(58.0 ; 128.0)$ & $66.0(50.0 ; 137.0)$ & $<0.001$ \\
\hline Glycaemia (mmol/L) & $6.0(4.5 ; 10.5)$ & $6.0(5.0 ; 20.3)$ & 0.666 \\
\hline Plasma renin activity $(\mathrm{ng} / \mathrm{mL} / \mathrm{h})$ & $0.5(0.1 ; 5.5)$ & $0.3(0.1 ; 9.4)$ & 0.864 \\
\hline Aldosterone (ng/L) & $94.0(23.0 ; 315.0)$ & $91.0(21.0 ; 261.0)$ & 0.419 \\
\hline Aldosterone/renin ratio ${ }^{\dagger}$ & $12.9(1.6 ; 297.0)$ & $15.2(0.7 ; 153.0)$ & 0.881 \\
\hline \multicolumn{4}{|l|}{ Medication at randomization } \\
\hline Angiotensin-converting enzyme inhibitor & $30(81.1 \%)$ & $12(66.7 \%)$ & 0.314 \\
\hline$\beta$ blocker & $27(73.0 \%)$ & $14(77.8 \%)$ & 1.000 \\
\hline Calcium channel blocker & $32(86.5 \%)$ & $17(94.4 \%)$ & 0.651 \\
\hline Diuretics & $37(100.0 \%)$ & $18(100.0 \%)$ & - \\
\hline Angiotensin II receptor blocker & $15(40.5 \%)$ & $10(55.6 \%)$ & 0.389 \\
\hline$\alpha$ blocker & $5(13.5 \%)$ & $3(16.7 \%)$ & 1.000 \\
\hline Centrally acting antihypertensives & $19(51.4 \%)$ & $13(72.2 \%)$ & 0.160 \\
\hline Other antihypertensives & $2(5.4 \%)$ & $0(0.0 \%)$ & 1.000 \\
\hline Median number of antihypertensives & $4.0(3.0 ; 6.0)$ & $5.0(4.0 ; 7.0)$ & 0.302 \\
\hline
\end{tabular}

Data are mean (SD) when normally distributed and median $\left(5^{\text {th }}\right.$ and $95^{\text {th }}$ percentile range) when they have non-normal distributions. Categorical variables are number (\%). Statistical significance was tested by Mann Whitney $U$ test.

${ }^{\dagger}$ Calculated as serum aldosterone $(\mathrm{ng} / \mathrm{L}) /[10 \mathrm{x}$ plasma renin activity $(\mathrm{ng} / \mathrm{mL} / \mathrm{h})]$. 
Table 3. Change of patient characteristics at 8 weeks compared to baseline according to age.

\begin{tabular}{|c|c|c|c|c|c|}
\hline Patient characteristics & $\begin{array}{c}\text { Age } \\
\text { below/above } \\
\text { median }\end{array}$ & $\begin{array}{l}\text { Spironolactone } \\
\qquad(\mathrm{n}=55)\end{array}$ & $\begin{array}{l}\text { Placebo } \\
(n=56)\end{array}$ & $\begin{array}{l}\text { Between group } \\
\text { difference* }\end{array}$ & $P^{\dagger}$ \\
\hline \multicolumn{6}{|l|}{ Systolic BP } \\
\hline \multirow{2}{*}{$\begin{array}{l}\text { ABPM day-time systolic BP } \\
(\mathrm{mm} \mathrm{Hg})\end{array}$} & I & $-8.5( \pm 13.0)$ & $-4.9( \pm 11.0)$ & $-3.6(-9.7 ; 2.5)$ & 0.459 \\
\hline & II & $-10.1( \pm 12.4)$ & $-2.5( \pm 13.5)$ & $-7.5(-14.6 ;-0.4)$ & 0.028 \\
\hline \multirow{2}{*}{$\begin{array}{l}\text { ABPM night-time systolic BP } \\
(\mathrm{mm} \mathrm{Hg})\end{array}$} & I & $-8.3( \pm 14.9)$ & $-1.1( \pm 19.2)$ & $-7.2(-16.0 ; 1.6)$ & 0.055 \\
\hline & II & $-14.1( \pm 19.9)$ & $-4.5( \pm 15.7)$ & $-9.6(-19.5 ; 0.4)$ & 0.119 \\
\hline \multirow{2}{*}{$\begin{array}{l}\text { 24-h ABPM systolic BP } \\
(\mathrm{mm} \mathrm{Hg})\end{array}$} & I & $-9.3( \pm 11.1)$ & $-3.8( \pm 12.1)$ & $-5.4(-11.3 ; 0.5)$ & 0.069 \\
\hline & II & $-12.1( \pm 12.5)$ & $-4.2( \pm 13.7)$ & $-7.9(-15.1 ;-0.7)$ & 0.032 \\
\hline \multirow{2}{*}{$\begin{array}{l}\text { Office systolic BP } \\
(\mathrm{mm} \mathrm{Hg})^{\ddagger}\end{array}$} & I & $-9.8( \pm 15.6)$ & $-6.1( \pm 17.5)$ & $-3.8(-12.2 ; 4.7)$ & 0.303 \\
\hline & II & $-19.6( \pm 14.3)$ & $-10.8( \pm 9.6)$ & $-8.9(-15.6 ;-2.1)$ & 0.012 \\
\hline \multicolumn{6}{|l|}{ Diastolic BP } \\
\hline \multirow{2}{*}{$\begin{array}{l}\text { ABPM day-time diastolic BP } \\
(\mathrm{mm} \mathrm{Hg})\end{array}$} & I & $-4.5( \pm 10.0)$ & $-2.6( \pm 8.7)$ & $-1.9(-6.6 ; 2.8)$ & 0.263 \\
\hline & II & $-3.8( \pm 5.5)$ & $-3.9( \pm 7.6)$ & $0.1(-3.5 ; 3.8)$ & 0.947 \\
\hline \multirow{2}{*}{$\begin{array}{l}\text { ABPM night-time diastolic BP } \\
(\mathrm{mm} \mathrm{Hg})\end{array}$} & I & $-5.6( \pm 9.0)$ & $-0.4( \pm 11.8)$ & $-5.1(-10.5 ; 0.2)$ & 0.054 \\
\hline & II & $-5.6( \pm 12.1)$ & $-5.4( \pm 9.3)$ & $-0.2(-6.2 ; 5.8)$ & 0.706 \\
\hline \multirow{2}{*}{$\begin{array}{l}\text { 24-h ABPM diastolic BP } \\
(\mathrm{mm} \mathrm{Hg})\end{array}$} & I & $-4.0( \pm 8.0)$ & $-2.5( \pm 8.0)$ & $-1.5(-5.6 ; 2.5)$ & 0.548 \\
\hline & II & $-4.4( \pm 5.9)$ & $-4.1( \pm 7.4)$ & $-0.2(-3.9 ; 3.4)$ & 0.630 \\
\hline \multirow{2}{*}{$\begin{array}{l}\text { Office diastolic BP } \\
(\mathrm{mm} \mathrm{Hg})^{\ddagger}\end{array}$} & I & $-5.6( \pm 10.2)$ & $-2.8( \pm 9.4)$ & $-2.9(-7.8 ; 2.1)$ & 0.106 \\
\hline & II & $-7.6( \pm 9.0)$ & $-5.9( \pm 7.0)$ & $-1.8(-6.2 ; 2.7)$ & 0.520 \\
\hline \multicolumn{6}{|l|}{ Pulse pressure ${ }^{\S}$} \\
\hline \multirow{2}{*}{$\begin{array}{l}\text { ABPM day-time pulse pressure } \\
(\mathrm{mm} \mathrm{Hg})\end{array}$} & I & $-4.0( \pm 8.2)$ & $-2.3( \pm 6.9)$ & $-1.7(-5.5 ; 2.1)$ & 0.411 \\
\hline & II & $-6.3( \pm 8.7)$ & $1.4( \pm 9.6)$ & $-7.7(-12.7 ;-2.7)$ & 0.005 \\
\hline \multirow{2}{*}{$\begin{array}{l}\text { ABPM night-time pulse pressure } \\
(\mathrm{mm} \mathrm{Hg})\end{array}$} & I & $-2.7( \pm 11.6)$ & $-0.7( \pm 10.0)$ & $-2.1(-7.5 ; 3.4)$ & 0.270 \\
\hline & II & $-8.5( \pm 13.6)$ & $0.9( \pm 11.1)$ & $-9.4(-16.2 ;-2.5)$ & 0.005 \\
\hline \multirow{2}{*}{$\begin{array}{l}\text { 24-h ABPM pulse pressure } \\
(\mathrm{mm} \mathrm{Hg})\end{array}$} & I & $-5.3( \pm 6.3)$ & $-1.4( \pm 5.6)$ & $-3.9(-6.9 ;-0.9)$ & 0.006 \\
\hline & II & $-7.7( \pm 8.0)$ & $-0.1( \pm 9.8)$ & $-7.6(-12.5 ;-2.8)$ & 0.006 \\
\hline \multirow{2}{*}{$\begin{array}{l}\text { Office pulse pressure } \\
(\mathrm{mm} \mathrm{Hg})^{\ddagger}\end{array}$} & I & $-4.2( \pm 11.2)$ & $-3.3( \pm 13.0)$ & $-0.9(-7.1 ; 5.3)$ & 0.865 \\
\hline & II & $-12.0( \pm 10.0)$ & $-4.9( \pm 10.0)$ & $-7.1(-12.6 ;-1.6)$ & 0.013 \\
\hline
\end{tabular}

Data are mean (SD). Age groups are defined according to median: I ( $\leq 62$ years), II ( $>62$ years). There are 28 and 27 patients below and above median respectively in spironolactone group and 32 and 24 patients below and above median respectively in placebo group.

*Difference between spironolactone and placebo group is expressed as difference in their means supplemented by $95 \%$ confidence interval. ${ }^{\dagger}$ Statistical significance was tested by Mann-Whitney U test. ${ }^{*}$ Average of $2^{\text {nd }}$ and $3^{\text {rd }}$ office BP measurements. ${ }^{8} C a l c u l a t e d$ as systolic BP minus diastolic BP in all measured parameters. 
Table 4. Change of patient characteristics after 8 weeks of spironolactone treatment*.

\begin{tabular}{lccc}
\hline Patient characteristics & Men & Women & $P$ \\
\hline Spironolactone group (N) & 37 & 18 & \\
\hline Systolic BP & & & \\
ABPM day-time systolic BP (mmHg) & $-8.3( \pm 12.9)$ & $-11.2( \pm 12.2)$ & 0.484 \\
ABPM night-time systolic BP (mmHg) & $-8.8( \pm 15.7)$ & $-15.9( \pm 20.8)$ & 0.244 \\
24-h ABPM systolic BP (mmHg) & $-9.5( \pm 11.6)$ & $-13.0( \pm 12.0)$ & 0.306 \\
Office systolic BP (mmHg) & $-13.8( \pm 12.0)$ & $-16.4( \pm 21.5)$ & 0.389 \\
\hline Diastolic BP & & & \\
ABPM day-time diastolic BP (mmHg) & $-4.2( \pm 8.2)$ & $-4.2( \pm 7.8)$ & 0.774 \\
ABPM night-time diastolic BP (mmHg) & $-5.1( \pm 9.3)$ & $-6.7( \pm 12.9)$ & 0.414 \\
24-h ABPM diastolic BP (mmHg) & $-4.4( \pm 7.1)$ & $-3.7( \pm 6.8)$ & 0.753 \\
Office diastolic BP (mmHg) & $-6.2( \pm 10.1)$ & $-7.3( \pm 8.7)$ & 0.936 \\
\hline Pulse pressure & & & \\
ABPM day-time pulse pressure (mmHg) & $-4.2( \pm 8.5)$ & $-7.0( \pm 8.2)$ & 0.255 \\
ABPM night-time pulse pressure (mmHg) & $-3.8( \pm 11.2)$ & $-9.3( \pm 15.4)$ & 0.103 \\
24-h ABPM pulse pressure (mmHg) & $-5.1( \pm 7.1)$ & $-9.3( \pm 6.7)$ & 0.037 \\
Office pulse pressure (mmHg) & $-7.5( \pm 8.3)$ & $-9.1( \pm 15.9)$ & 0.713 \\
\hline
\end{tabular}

*Compared to baseline according to sex. Data are mean (SD). Statistical significance was tested by Mann Whitney U test.

${ }^{\S}$ Calculated as systolic BP minus diastolic BP in all measured parameters.

Richter Gedeon Ltd., Czech Republic) or currently using any aldosterone antagonist (spironolactone, eplerenone or canreonate).

Patients were randomly assigned in a one-to-one ratio to receive either spironolactone at a dose of $25 \mathrm{mg}$ once daily or a placebo once daily in the morning, as an addon to their current antihypertensive therapy, in a blinded manner. After randomization, patients were followed for 8 weeks. Office blood pressure was recorded by a calibrated mercury sphygmomanometer in seated patients with their arm supported as the average of the 2 nd and 3rd measurements. At baseline and 8 weeks, 24-h ambulatory blood pressure monitoring (ABPM) was performed using validated devices ${ }^{16,17}$. Average day-time blood pressure was calculated from values measured between 09:00 and 21:00, average night-time blood pressure from values measured between 01:00 and 06:00 and average 24-hour blood pressure was calculated from all the values recorded by ABPM (ref. ${ }^{18}$ ).

Serum sodium, potassium, chlorides, urea and creatinine, plasma renin activity (PRA), plasma aldosterone and aldosterone/renin ratio (ARR), microalbuminuria and proteinuria in a 24-h urine sample were measured at baseline and at 8 weeks. Patients did not change the dosage or quantity of their antihypertensive medication throughout the trial.
To perform this analysis, patients were stratified by baseline age and sex. Standard descriptive statistics were applied in the analysis. Continuous variables were described using mean and standard deviation when the prerequisite of normality was fulfilled, and the median and $5^{\text {th }}$ and $95^{\text {th }}$ percentile range in case of non-normal distribution. Categorical variables were described by the number of cases and the percentages of categories. The statistical significance of differences between groups was analyzed using the Mann Whitney U test and the Kruskal Wallis test. Statistical analysis was computed using SPSS 19.0.1 (IBM Corporation, New York, U.S.A.).

\section{RESULTS}

A total of 117 patients were enrolled in the trial from September 2007 to June 2010, with follow-up during the following 2 months. The trial profile has been published. Of the 59 and 58 patients enrolled into the spironolactone and placebo arms, 4 and 2 patients discontinued treatment prematurely (due to adverse events or protocol violation). Analyses were done with 55 patients who were treated with spironolactone and 56 patients treated by placebo who finished the trial.

To assess whether the effect of spironolactone depended on age, patients were divided into two groups based on 
the median age of the spironolactone group (62 years). Baseline characteristics of the patients according to age groups and sex are shown in Tables 1 and 2. The mean office BP was 155/93 mmHg, mean 24-hour ABPM blood pressure was $143 / 81 \mathrm{mmHg}$. Isolated systolic hypertension (office systolic BP >140 mmHg and diastolic BP $<90$ $\mathrm{mmHg}$ ) was present in $36.4 \%$ of patients. Patients were using a mean of 4.6 antihypertensive drugs. All patients used diuretics, mostly hydrochlorothiazide or indapamide.

When compared to placebo, only patients with a median age $>62$ years had significant reductions of office systolic BP $(-8.9 \pm 6.7 \mathrm{mmHg}, P=0.012)$, 24-h ABPM systolic $\mathrm{BP}(-7.9 \pm 7.2 \mathrm{mmHg}, P=0.032)$ and ABPM day-time systolic BP $(-7.5 \pm 7.1 \mathrm{mmHg})$ after 8 weeks of spironolactone treatment (see Table 3 ). The respective systolic BP reductions in patients aged $\leq 62$ years were not statistically significant. Diastolic BP was not significantly influenced by spironolactone treatment in either group (Table 3 ).

Of the 55 patients treated with spironolactone, 37 were men and 18 women. Women had a significantly larger 24-h ABPM pulse pressure reduction (-9.3 \pm 6.7 $\mathrm{mmHg})$ compared to men $(-5.1 \pm 7.1 \mathrm{mmHg})(P=0.037)$ (see Table 4 ), but tended to have only a nonsignificantly larger reduction in systolic BP with spironolactone treatment, and there was no difference in diastolic BP reduction between women and men (Table 4).

\section{DISCUSSION}

This subanalysis of a randomized trial showed that the addition of spironolactone in patients with resistant arterial hypertension using a mean of 4.6 antihypertensive drugs, led to a reduction in systolic BP only in older patients. Spironolactone treatment was effective to a similar extent in men and women with resistant arterial hypertension.

Several trials reported conflicting data on whether the BP response to spironolactone can be predicted by age and sex. In one of the earliest reports by Nishizaka et al., no significant correlation was found between the degree of $\mathrm{BP}$ reduction and age, body mass index and baseline biochemical parameters ${ }^{3}$. In the retrospective evaluation of a cohort of 344 patients by Engbaek et al., a numerically larger reduction in systolic BP $(-26.6 \mathrm{mmHg}$ at 3 months), but not diastolic BP $(-9.2 \mathrm{mmHg}$ at 3 months $)$, was observed with low-dose spironolactone treatment in women compared to men $(-20.6 \mathrm{mmHg}$ and $-10.2 \mathrm{mmHg}$ at 3 months) (ref. ${ }^{11}$ ).

In a multivariate analysis of a prospective trial of 175 patients by de Souza et al., age and sex were not independently associated with a systolic BP decrease during spironolactone administration (sex, $P=0.33$, and age, $P=0.78)$ or satisfactory $(>10 \%)$ systolic $\mathrm{BP}$ response to spironolactone (sex, $P=0.39$, age, $P=0.82$ ) (ref. ${ }^{10}$ ). The only factors associated with better response were greater waist circumference, lower aortic pulse wave velocity, and lower serum potassium ${ }^{10}$.

In the nonrandomized post-hoc analysis of the AngloScandinavian Cardiac Outcomes Trial-Blood Pressure
Lowering Arm by Chapman et al., there were modest but significantly greater reductions in diastolic BP among patients aged $60+$ compared with younger participants (difference $-2.86 \mathrm{mmHg}, P<0.001$ ), among women compared to men (difference $-1.78 \mathrm{mmHg}, P=0.002$ ), and among participants with diabetes compared with those without (difference $-1.13 \mathrm{mmHg}, P=0.025$ ) $\left(\right.$ ref. $^{6}$ ).

A prospective trial comparing the spironolactone and doxazosin treatment in resistant hypertension by Rodilla et al., found that patients who achieved BP control with treatment were younger (63 years compared to 67 years, $P=0.04$ ), with lower glucose levels, and fewer had metabolic syndrome or diabetes ${ }^{19}$.

In a cohort of 46 patients with resistant hypertension and chronic kidney disease stage 2 or 3 reported by Khosla et al., female gender with $\mathrm{BMI} \geq 30$ predicted greater systolic BP response to aldosterone antagonism ( $15 \pm 8 \mathrm{mmHg}$ in women, $-8 \pm 6 \mathrm{mmHg}$ in men) with an odds ratio of $1.31(P=0.04)$ (ref. $\left.^{7}\right)$. Another paper by Mahmud et al. reported a significant correlation between age and the fall in systolic BP $(r=0.39, P<0.05)$ but not diastolic BP ( $r=0.05$, NS) $\left(\right.$ ref. $\left.^{20}\right)$.

Vascular stiffness is one of the major factors contributing to resistant hypertension. Stiffness of the arterial wall in conductance arteries increases with increasing age, leading to increased pulse wave velocity. The reflected pressure wave returns to the heart not in the diastole but in the end of the systole, thus increasing systolic blood pressure $^{21}$. Recent randomized trials showed that spironolactone predominantly decreased systolic BP, more than diastolic BP (ref. ${ }^{14,22}$ ). Spironolactone also, significantly more than thiazide diuretics, reduced pulse wave velocity and augmentation index ${ }^{23}$. We postulated that, because of these properties, spironolactone could be an effective treatment for older patients with isolated systolic hypertension ${ }^{14}$. The decrease of arterial stiffness by spironolactone might explain its effect on systolic blood pressure predominantly in older people aged $>62$ years in this analysis. Despite the higher baseline diastolic BP in patients aged $\leq 62$ years in our trial the reduction of diastolic BP with spironolactone was comparable in both age groups.

Both in clinical trials and in clinical practice the decision to recommend spironolactone is influenced by the patients' age and sex, with reluctance to recommend this agent to young men in order to avoid possible adverse effects on sexual function ${ }^{5}$. However, low doses of $25 \mathrm{mg}$ spironolactone daily have a low occurrence of side effects - around 7\% a year ${ }^{6}$. This analysis shows that a similar BP lowering effect of spironolactone can be expected both in men and women with resistant hypertension.

A potential limitation of this analysis is the relatively small sample size. It is possible that recruitment of a substantially larger number of patients could have shown a more pronounced effect of spironolactone in certain subgroups.

In conclusion, this analysis shows that spironolactone treatment only leads to a reduction of systolic BP in older patients aged $>62$ years with resistant arterial hypertension, and is effective to a similar extent in men and women. Since spironolactone is a cheap and widely 
available drug, its use in older patients with isolated systolic hypertension is appealing, but needs to be explored in further studies.

\section{ACKNOWLEDGEMENT}

This work was supported by a restricted grant from the Czech Society for Hypertension. Richter Gedeon Ltd. (Czech Republic) provided the spironolactone for the preparation of the randomized medication and covered trial insurance.

This output has been created within Operational Program Education for Competitiveness, project Partnership and Cooperation in the Field of eHealth, ID: CZ.1.07/2.4.00/17.0071, and is co-financed by European Social Fund and the state budget of the Czech Republic.

Authorship contributions: JV, JJ: study design; JV: literature search; JV, RS, EK: data collection; JV, JJ: data analysis; JJ: statistical analysis, tables; JV, JJ, MT: data interpretation; JV: manuscript writing; RS, JJ, EK, MT: manuscript revision, JV, RS, EK, JJ, MT: final approval.

Conflict of interest statement: The authors stated that there are no conflicts of interest regarding the publication of this article.

\section{REFERENCES}

1. Calhoun DA, Jones D, Textor S, Goff DC, Murphy TP, Toto RD, White A, Cushman WC, White W, Sica D, Ferdinand K, Giles TD, Falkner B, Carey RM. Resistant hypertension: diagnosis, evaluation, and treatment. A scientific statement from the American Heart Association Professional Education Committee of the Council for High Blood Pressure Research. Hypertension 2008;51:1403-19.

2. Ouzan J, Pérault C, Lincoff AM, Carré E, Mertes M. The role of spironolactone in the treatment of patients with refractory hypertension. Am J Hypertens 2002;15:333-9.

3. Nishizaka MK, Zaman MA, Calhoun DA. Efficacy of low-dose spironolactone in subjects with resistant hypertension. Am J Hypertens 2003;16:925-30.

4. Sharabi Y, Adler E, Shamis A, Nussinovitch N, Markovitz A, Grossman E. Efficacy of add-on aldosterone receptor blocker in uncontrolled hypertension. Am J Hypertens 2006;19:750-5.

5. Lane DA, Shah S, Beevers DG. Low-dose spironolactone in the management of resistant hypertension: a surveillance study. J Hypertens 2007;25:891-4.

6. Chapman N, Dobson J, Wilson S, Dahlöf B, Sever PS, Wedel H, Poulter NR; Anglo-Scandinavian Cardiac Outcomes Trial Investigators. Anglo-Scandinavian Cardiac Outcomes Trial Investigators. Effect of spironolactone on blood pressure in subjects with resistant hypertension. Hypertension 2007;49:839-45.
7. Khosla N, Kalaitzidis R, Bakris GL. Predictors of hyperkalemia risk following hypertension control with aldosterone blockade. Am J Nephrol 2009;30(5):418-24.

8. Ubaid-Girioli S, Adriana de Souza L, Yugar-Toledo JC, Martins LC, Ferreira-Melo S, Coelho OR, Sierra C, Coca A, Pimenta E, Moreno H. Aldosterone excess or escape: Treating resistant hypertension. J Clin Hypertens (Greenwich) 2009;11(5):245-52.

9. Alvarez-Alvarez B, Abad-Cardiel M, Fernandez-Cruz A, Martell-Claros N. Management of resistant arterial hypertension: role of spironolactone versus double blockade of the renin-angiotensin-aldosterone system. J Hypertens 2010;28(11):2329-35.

10. de Souza F, Muxfeldt E, Fiszman R, Salles G. Efficacy of spironolactone therapy in patients with true resistant hypertension. Hypertension 2010;55(1):147-52.

11. Engbaek M, Hjerrild M, Hallas J, Jacobsen IA. The effect of low-dose spironolactone on resistant hypertension. J Am Soc Hypertens 2010;4(6):290-4.

12. Abolghasmi R, Taziki O. Efficacy of low dose spironolactone in chronic kidney disease with resistant hypertension. Saudi J Kidney Dis Transpl 2011;22(1):75-8.

13. Václavík J, Kociánová E, Táborský M. Use of spironolactone in the treatment of resistant arterial hypertension. Cor Vasa 2011;53:343-7.

14. Václavík J, Sedlák R, Plachý M, Navrátil K, Plášek J, Jarkovský J, Václavík T, Husár R, Kociánová E, Táborský M. Addition of Spironolactone in Patients With Resistant Arterial Hypertension (ASPIRANT): A Randomized, Double-Blind, Placebo-Controlled Trial. Hypertension 2011;57(6):1069-75.

15. Vaclavik J, Sedlak R, Plachy M, Navratil K, Plasek J, Husar R, Kocianova $\mathrm{E}$, Taborsky M. Addition of spironolactone in patients with resistant arterial hypertension (ASPIRANT) - study protocol. Biomed Pap Med Fac Univ Palacky Olomouc Czech Repub 2011;155(2):143-8.

16. O'Brien E, Waeber B, Parati G, Staessen J, Myers MG, on behalf of the European Society of Hypertension Working Group on Blood Pressure Monitoring. Blood pressure measuring devices: recommendations of the European Society of Hypertension. Brit Med J 2001;322:531-6.

17. Association for the Advancement of Medical Instrumentation. American national standard. Electronic or automated sphygmomanometers. Arlington, VA:AAMI;1993.

18. O'Brien E, Waeber B, Parati G, Staessen J, Myers MG, on behalf of the European Society of Hypertension Working Group on Blood Pressure Monitoring. Practice guidelines of the European Society of Hypertension for clinic, ambulatory and self blood pressure measurement. J Hypertens 2005;23:697-701.

19. Rodilla E, Costa JA, Pérez-Lahiguera F, Baldó E, González C, Pascual JM. Spironolactone and doxazosin treatment in patients with resistant hypertension. Rev Esp Cardiol 2009;62(2):158-66.

20. Mahmud A, Mahgoub M, Hall M, Feely J. Does aldosterone-to-renin ratio predict the antihypertensive effect of the aldosterone antagonist spironolactone? Am J Hypertens 2005;18(12 Pt 1):1631-5.

21. Lee HY, Oh BH. Aging and arterial stiffness. Circ J 2010;74(11):225762.

22. Saha C, Eckert GJ, Ambrosius WT, Chun TY, Wagner MA, Zhao Q, Pratt JH. Improvement in blood pressure with inhibition of the epithelial sodium channel in blacks with hypertension. Hypertension 2005;46:481-7.

23. Mahmud A, Feely J. Aldosterone-to-renin ratio, arterial stiffness, and the response to aldosterone antagonism in essential hypertension. Am J Hypertens 2005;18:50-5. 